
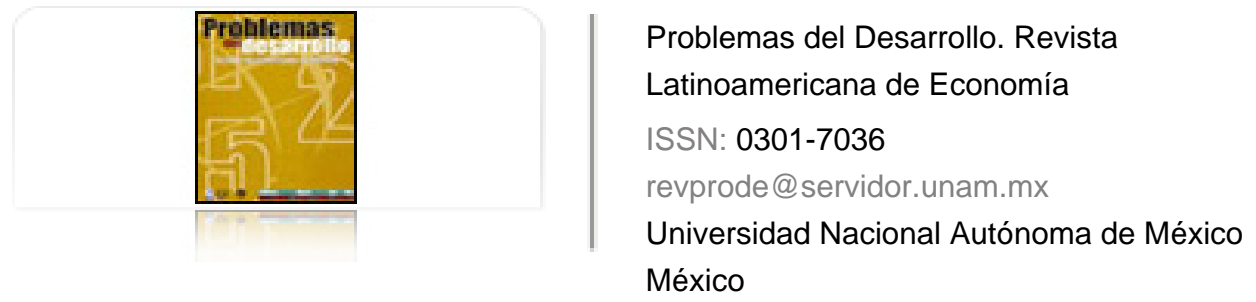

Vitto, Cecilia

Plan económico del tercer gobierno peronista. Gestión de Gelbard (1973-1974)

Problemas del Desarrollo. Revista Latinoamericana de Economía, vol. 43, núm. 171, octubrediciembre, 2012, pp. 111-134

Universidad Nacional Autónoma de México

Distrito Federal, México

Disponible en: http://www.redalyc.org/articulo.oa?id=11823951006

Cómo citar el artículo

- Número completo

- Más información del artículo

Página de la revista en redalyc.org

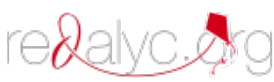

Sistema de Información Científica

Red de Revistas Científicas de América Latina, el Caribe, España y Portugal Proyecto académico sin fines de lucro, desarrollado bajo la iniciativa de acceso abierto 


\title{
Plan ECONÓMico DEL TERCER GOBIERNO PERONISTA. GESTIÓN DE GELBARD (I973-I974) ${ }^{1}$
}

\author{
Cecilia Vitto*
}

Fecha de recepción: 12 de noviembre del 2011. Fecha de aceptación: 07 de marzo del 2012.

\section{RESUMEN}

El tercer gobierno peronista (1973-1976) se proponía llevar a cabo una profunda reestructuración del capitalismo argentino, a partir de la puesta en práctica de un ambicioso programa estructural que buscaba fomentar el desarrollo nacional, establecía una planificación integral de la economía y abarcaba múltiples aspectos de la vida económica. En este marco, este trabajo busca analizar la política económica desarrollada por el ministro de Hacienda y Finanzas José Ber Gelbard (mayo de 1973-octubre de 1974). Se pretende examinar el proyecto de reforma estructural y las políticas económicas de corto plazo, evaluar las principales consecuencias de la política implementada en términos de la evolución de los principales indicadores económicos y reflexionar sobre las principales debilidades del programa económico.

Palabras clave: peronismo, Gelbard, Plan Trienal para la Reconstrucción y la Liberación Nacional, burguesía nacional, política económica.

\section{The Third Peronist Government's Economic Plan. Gelbard's Term (I973-I974)}

\begin{abstract}
The third Peronist government (1973-1976) carried out a profound restructuring of Argentinean capitalism, initially by implementing an ambitious structural program that sought to foster national development, establish comprehensive economic planning and encompass multiple aspects of economic life. In this framework, this work seeks to analyze the economic policy developed by Treasury and Finance Minister José Ber Gelbard (May 1973 to October 1974). This study aims to examine the project of structural reform and short-term economic policy, evaluate the main consequences of the policies implemented in terms of how key economic indicators evolved and reflect on the major weaknesses of the economic program.
\end{abstract}

Key Words: peronism, Gelbard, Triennial Plan for National Reconstruction and Liberation, national bourgeoisie, economic policy.

1 Se agradecen los valiosos comentarios realizados por Daniel Azpiazu y Eduardo Basualdo, eximiéndolos de toda responsabilidad en cuanto a eventuales errores u omisiones.

* Becaria del Consejo Nacional de Investigaciones Cientificas y Técnicas (FLACSO, Argentina). Correo electrónico: ceciliavitto@gmail.com 


\section{PLAN ÉCONOMIQUE DU TROISIÈME GOUVERNEMENT PÉRONISTE : GESTION DE GELBARD (1973-1974) \\ Résumé}

Le troisième gouvernement péroniste (1973-1976) se proposait de mener à bien une profonde restructuration du capitalisme argentin, à partir de la mise en œuvre d'un ambitieux programme structurel visant à fomenter le développement national, qui établissait une planification intégrale de l'économie et englobait de multiples aspects de la vie économique. Dans ce contexte, ce travail tente d'analyser la politique économique développée par le ministre des Finances José Ber Gelbard (mai 1973 octobre 1974). Il prétend examiner le projet de réforme structurelle et les politiques économiques à court terme, évaluer les principales conséquences de la politique mise en œuvre en termes d'évolution des principaux indicateurs économiques et présenter une réflexion sur les principales faiblesses du programme économique.

Mots clés: péronisme, Gelbard, Plan Triennal pour la Reconstruction et la Libération Nationale, bourgeoisie nationale, politique économique.

\section{PLANO ECONÓMICO DO TERCEIRO GOVERNO PERONISTAS: GESTÁO DE GELBARD (1973-1974) \\ Resumo}

O terceiro governo peronista (1973-1976) propunha levar a cabo uma profunda reestruturação do capitalismo argentino, a partir da implantação de um ambicioso programa estrutural que buscava fomentar o desenvolvimento nacional, estabelecia um planejamento integral da economia e abarcava múltiplos aspectos da vida econômica. Neste marco, este trabalho busca analisar a politica econômica desenvolvida pelo ministro de Fazenda y Finanças Jose Ber Gelbard (maio de 1973-outubro de 1974). Pretende-se examinar o projeto de reforma estrutural e as politicas econômicas de curto prazo, avaliar as principias consequências da política implantada em termos da evolução dos principias indicadores econômicos e refletir sobre as principais fraquezas do programa econômico.

Palavras-chave: peronismo, Gelbard, Plan Trienal para la Reconstrucción y la Liberación Nacional, burguesía nacional, política económica.

\section{第三届庇隆主义政府的经济计划：盖尔伯特任期（1973 1974） 摘要}

第三届庇隆主义政府(1973 1976)对阿根廷的资本主义进行了深度重组。该计 划最初是执行了一项雄伟的结构性项目, 寻求促进国家发展、制定全面的经济 规划, 并包含多种因素的经济生活。根据这一背景, 本文试图分析时任财政和 金融部长何塞・伯尔・盖尔伯特（1973年5月至1974年10月）的经济政策。该 研究旨在分析这一时期阿根廷结构性改革的项目和短期经济政策, 并使用相关 经济指标, 评估执行这些政策后的主要后果, 同时, 对这项经济改革计划的脆 弱性做出反思。

关键词：庇隆主义盖尔伯特国家重组和自由化的三年计划国家资产阶级经 济政策 


\section{INTRODUCCIÓN}

El análisis de la política económica llevada a cabo durante el tercer gobierno peronista argentino (1973-1976) debe ser realizado en referencia a su contexto histórico, es decir, a lo acaecido durante la segunda etapa del régimen de acumulación basado en la industrialización por sustitución de importaciones. La misma tuvo lugar a partir de finales de la década de 1950, cuando el gobierno de Frondizi impulsó una política que implicó una entrada masiva de capitales extranjeros al país, con el fin proclamado de lograr incrementos de producción y productividad que redundaran en el crecimiento de la economía y en la resolución de la brecha externa.

Durante esta etapa se verificó una consolidación del predominio extranjero sobre el proceso económico a partir del control de los núcleos técnicos y económicos de las cadenas productivas centrales, afianzándose una estructura industrial oligopólica en la cual las grandes firmas detentaban la capacidad de definir la estructura de precios relativos (Azpiazu, Basualdo y Khavisse, 2004).

La economía local evolucionó sobre la base de un comportamiento cíclico de corto plazo del producto, cobrando vigencia las fases conocidas como pare-siga o stop and go (Braun y Joy, 1981; Diamand, 1977). Sin embargo, en la segunda fase de la industrialización sustitutiva se pueden establecer dos etapas claramente diferenciadas, con tasas de crecimiento disímiles (Brodersohn, 1973; Basualdo, 2006). Mientras que hasta el año 1963 (inclusive) los ciclos de corto plazo acarrearon en la fase descendente una disminución del producto en términos absolutos, entre 1964 y 1974 el producto bruto creció ininterrumpidamente, sobre la base de un ciclo corto con aceleraciones y desaceleraciones de la tasa de crecimiento. Esta modificación del ciclo se encuentra asociada a la maduración de las inversiones realizadas a partir de la incorporación de capital extranjero, que redundó en la presencia de actividades de tecnologías más complejas y de mayor intensidad relativa en el uso del capital, y en un cambio significativo en la situación del comercio exterior, fundamentalmente a partir del incremento de las exportaciones totales y específicamente las de origen industrial (Basualdo, 2006).

En el marco de esta situación estructural, el programa económico inicial del tercer gobierno peronista residía, fundamentalmente, en la implementación del Plan Trienal para la Reconstrucción y la Liberación Nacional. Este plan establecía una planificación integral de la economía que buscaba fomentar el desarrollo nacional y que abarcaba múltiples aspectos de la vida económica; el mismo se proponía obtener la plena vigencia de la justicia social, garantizar una alta calidad de vida, reconstruir el Estado, redimensionar las relaciones de fuerza en 
el agro y en la industria, y recuperar la independencia económica en lo que respecta al rol de la inversión y el financiamiento externo en el desarrollo del país.

Asimismo, la política de ingresos se constituía en uno de los pilares principales del plan económico. En efecto, la política económica llevada a cabo por Gelbard tuvo, como uno de sus núcleos centrales, el denominado "Pacto Social" que consistió en una política concertada entre los sindicatos (la CGT), los empresarios nacionales (la CGE) y el Estado que incluía, luego de un incremento salarial inicial, un congelamiento de precios y salarios.

En este marco, el objetivo de este trabajo es analizar la política económica llevada a cabo durante el tercer gobierno peronista, y en particular durante la gestión de José Ber Gelbard (mayo de 1973-octubre de 1974), y evaluar las principales debilidades de la misma en la promoción del desarrollo nacional.

El artículo está integrado por cinco apartados. En el primero se analizan las principales características del programa económico en lo referente a las proyecciones establecidas, y a la política de ingresos y de precios llevada a cabo. En el segundo se consideran algunas de las principales medidas estructurales, en relación con la profusa legislación sancionada durante el periodo y la implementación del Plan Trienal. En el tercero se evalúan las principales consecuencias de la política implementada, en términos de la evolución de los principales indicadores económicos. En el cuarto se indagan las principales debilidades del programa económico. Por último, se presentan las reflexiones del trabajo.

\section{PRINCIPALES LINEAMIENTOS DEL PROGRAMA ECONÓMICO}

Luego de dieciocho años de proscripción, el 25 de mayo de 1973 el peronismo retorna formalmente al gobierno. El tercer gobierno peronista aunaba una diversidad de sectores con orientaciones y expectativas sumamente disímiles e incluso contrapuestas, cuya unidad se asentaba, básicamente, en la indiscutible figura de Perón. El núcleo central de la alianza que representaba el regreso del peronismo al poder y de la política económica que se pondría en marcha, se encontraba en el movimiento sindical organizado en la CGT y en la agrupación empresaria que reunía a los pequeños y medianos empresarios nacionales (la CGE). La propuesta de dicha alianza tenía como uno de sus estandartes principales la defensa del mercado interno y de un capitalismo "nacional", con pleno empleo y con una distribución del ingreso favorable a los asalariados. ${ }^{2}$

2 Dentro de la alianza que llegaba al poder en 1973 se encontraban también los grupos juveniles de izquierda, los cuales habían tenido un significativo protagonismo en los años finales de la 
Se buscaba, por un lado, dotar al sector público de instrumentos que hicieran factible este proceso. Por otro lado, se pretendía estimular el desarrollo del sector privado nacional en pos de contrarrestar el poder económico del capital extranjero y de la "oligarquía nacional" y revertir el proceso de desnacionalización y dependencia, a partir de la promoción del desarrollo de las pequeñas y medianas empresas (PYMEs).

Una de las intenciones prioritarias del programa inicial del tercer gobierno peronista era la búsqueda para compatibilizar la acumulación de capital con una distribución del ingreso más equitativa. El Plan preveía alcanzar, entre 1973 y 1977, una tasa de crecimiento de la producción de bienes y servicios del 7.5\% anual acumulativo, ritmo que se apoyaría en una alta tasa de incremento de la inversión, en el aumento de la productividad del capital instalado y en la duplicación del volumen de las exportaciones de mercancías. Estas previsiones suponían una reorganización de la estructura económica y del capital que se encontraba asociada, fundamentalmente, a la promoción de las PYMES, al estímulo a las exportaciones industriales y a la redefinición del papel del Estado.

En consonancia con esto último, como se observa en el Cuadro 1, se proyectaba que el apreciable incremento en el nivel de la formación anual de capital sería acompañado por un cambio en su composición (con un aumento significativamente mayor de la inversión pública). El logro de esta meta implicaba un crecimiento del PBI mayor al incremento del consumo, lo que suponía modificaciones en ciertos comportamientos de la sociedad y en particular en la propensión al ahorro.

Asimismo, el ritmo proyectado de crecimiento de la economía debía ser un medio en pos de conducir a una transformación profunda de la estructura socioeconómica del país, considerándose esencial alcanzar una distribución equitativa de los logros del progreso económico. El Acta de Compromiso Nacional (ACN) y el Plan Trienal para la Reconstrucción y la Liberación Nacional pretendían garantizar para el año 1977 una participación de los asalariados en el ingreso similar a la de 1955 (47.7\%), lo que significaba un aumento de más de 5 puntos porcentuales respecto del valor de 1973.

\footnotetext{
"Revolución Argentina" y durante la campaña electoral -siendo alentados por Perón desde su exilio en Madrid- y se encontraban a la espera de reafirmar su posición dentro del movimiento, en detrimento de la "burocracia sindical", con la que estaban fuertemente enfrentados. Otra disputa central tenía lugar en el interior de la burguesía nacional, entre los integrantes vinculados a la producción de bienes salarios no exportables (fundamentalmente textil y alimentos) y los asentados en producciones dinámicas subordinadas a las empresas trasnacionales (como las automotrices) a las que estaba vinculado el ministro de Economía.
} 
Cuadro 1

Proyecciones Plan Trienal. PBI a costo de factores, Inversión bruta interna, Inversión pública, Consumo privado y Consumo total, 1973, 1977 y tasa de crecimiento anual acumulativa

(en millones de pesos a precios de 1973 y porcentajes)

\begin{tabular}{lrrr}
\hline \multirow{2}{*}{ Conceptos } & \multicolumn{2}{c}{ Años } & \multicolumn{1}{c}{$\begin{array}{c}\text { Tasa de } \\
\text { crecimiento anual }\end{array}$} \\
\cline { 2 - 3 } PBI a costo de factores (en millones de pesos a precios de 1973) & \multicolumn{1}{c}{1973} & 1977 & $7.5 \%$ \\
Inversión bruta interna (en millones de pesos a precios de 1973) & 75.800 & 442.023 & 121.169 \\
Inversión pública (millones de pesos a precios de 1973) & 24.439 & 50.762 & $12.4 \%$ \\
Participación de la inversión pública en la inversión bruta interna & 32.2 & 41.9 & $20.1 \%$ \\
(en porcentajes) & & & \\
Consumo privado & 235.038 & 292.225 & $5.6 \%$ \\
Consumo total & 278.234 & 335.942 & $4.8 \%$ \\
\hline
\end{tabular}

Fuente: Poder Ejecutivo Nacional (1973).

De esta manera se buscaba fomentar una redistribución del ingreso a favor de los asalariados, a partir de un incremento de los salarios reales por encima de la productividad media de la economía, ${ }^{3}$ previéndose un incremento de los salarios reales del orden del 7\% anual acumulativo (Cuadro 2). Asimismo, se preveía una expansión del empleo que suponía el logro de la plena ocupación para el año 1977, proyección que se encontraba estrechamente asociada a las metas de crecimiento económico e inversión.

La política económica llevada a cabo por Gelbard tuvo, como uno de sus núcleos centrales, una política de ingresos concertada entre los sindicatos (CGT), los empresarios (CGE) y el Estado. A tal fin, una de las principales medidas que se puso en práctica fue un incremento de salarios (una suma fija de \$200) a partir del primero de junio de 1973, que debió ser absorbido en su totalidad por el sector no asalariado, respetándose asimismo los aumentos por convenios ya pactados. ${ }^{4}$ Una vez trasladados los mayores costos derivados del reajuste tarifario, los

3 Para una demostración matemática de que la participación de los trabajadores en el ingreso está en función de la relación entre el salario real y la productividad del trabajo, y que por lo tanto la participación se incrementa si el primero aumenta más que la segunda, véase Basualdo (2008: 312).

4 Este aumento suponía un intento de paliar la fragmentación salarial dado que, al ser igual para todos, impactaba en mayor medida en los sectores con menores ingresos (Testa, 1975: 61). Asimismo, se determinó un incremento de las asignaciones familiares (40\%) y de las jubilaciones (28\%), estableciéndose también un aumento de las tarifas de bienes y servicios suministrados por el sector público, el cual sería diferencial (tratando de que recayera sobre aquellos que tuvieran una mayor capacidad económica). 
precios debían mantenerse congelados hasta el $1^{\circ}$ de junio de 1975 . Así como estos últimos, los salarios también debían mantenerse congelados hasta esta fecha, con un ajuste a mediados de 1974 por aumento de productividad.

Cuadro 2. Proyecciones Plan Trienal. Participación de la remuneración de los asalariados en el ingreso, remuneración total de asalariados, remuneración real media anual y productividad, 1973, 1977 y tasa de crecimiento anual acumulativa (en porcentajes, millones de pesos a precios de 1973 y pesos a precios de 1973)

\begin{tabular}{lrrr}
\hline \multirow{2}{*}{ Conceptos } & \multicolumn{2}{c}{ Años } & \multicolumn{1}{c}{$\begin{array}{c}\text { Tasa de } \\
\text { crecimiento anual }\end{array}$} \\
\cline { 2 - 3 } & 1973 & 1977 & - \\
\hline Participación de la remuneración de asalariados* (en \%) & 42.5 & 47.7 & $10.6 \%$ \\
$\begin{array}{l}\text { Remuneración total de asalariados* (en millones de pesos a } \\
\text { precios 1973) }\end{array}$ & 140.672 & 210.844 & $7.0 \%$ \\
$\begin{array}{l}\text { Remuneración real media anual (en pesos a precios de 1973) } \\
\text { Productividad }\end{array}$ & 19.798 & 25.997 & $4.0 \%$ \\
\hline
\end{tabular}

* Comprende sueldos y salarios efectivamente percibidos y las correspondientes cargas sociales.

Fuente: Poder Ejecutivo Nacional (1973).

\section{ALGUNAS DE LAS PRINCIPALES MEDIDAS ESTRUCTURALES IMPLEMENTADAS}

Muchas de las leyes promulgadas en este periodo inicial tenían como uno de sus pilares fundamentales promover el crecimiento de la industria nacional y estimular el uso de la tecnología local (Poder Ejecutivo Nacional, 1973: 31), buscando favorecer especialmente a la burguesía nacional. ${ }^{5}$ Pueden distinguirse esencialmente cuatro leyes que buscaban servir a tales propósitos, que intentaban regular la entrada de capitales extranjeros (Ley $N^{\circ}$ 20.557), el funcionamiento de las pymes (Ley $\mathrm{N}^{\circ}$ 20.568), el trabajo y la producción nacional (Ley $\mathrm{N}^{\circ} 20.545$ ) y la promoción industrial (Ley $\left.\mathrm{N}^{\circ} 20.560\right)$.

En cuanto a la participación del capital extranjero, se buscaba permitir la misma solamente en tanto no limitara la capacidad decisoria del país, no

\footnotetext{
5 Esta fracción del capital se encontraba vinculada al abastecimiento del mercado interno a partir de la producción de bienes de consumo popular, siendo conducida por grandes firmas industriales oligopólicas con capacidad para establecer acuerdos con los sectores asalariados.
} 
significara una carga gravosa de futuros pagos y demostrara tener efectos positivos para el desarrollo nacional. Atenta a tales principios, la Ley $N^{\circ} 20.557$ establecía que en ningún caso podría otorgarse a inversores extranjeros tratamiento más favorable que a los nacionales, que los inversores extranjeros que desearan radicar capital en el país debían solicitar previamente autorización, y que no serían consentidas aquellas nuevas radicaciones que se destinasen a determinadas actividades, como las relacionadas con la defensa y seguridad nacional.

Este trato severo hacia el capital extranjero se complementaba con el estímulo a las empresas de capital nacional. Uno de los instrumentos para tal fin era la Corporación para el Desarrollo de la Pequeña y Mediana Empresa. Esta corporación, creada a partir de la Ley $\mathrm{N}^{\circ} 20.568$, buscaba fomentar la expansión de las PYMEs especialmente en el interior del país y generar una participación creciente de las mismas en el mercado interno, impulsando su mayor eficiencia y productividad, promoviendo su acceso al crédito, y propiciando la colocación de sus productos en el mercado internacional.

Asimismo, por medio de la Ley $\mathrm{N}^{\circ} 20.560$ de Promoción Industrial se pretendía, con base en un criterio selectivo y programado, otorgar apoyo estatal a aquellas unidades productivas que se determinaran como prioritarias en base a las necesidades del país, pudiendo presentarse solamente empresas de capital nacional.

Por último, a partir de la ley $\mathrm{N}^{\circ} 20.545$ de Defensa del Trabajo y la Producción Nacional, promulgada a fines de 1973, se buscaba favorecer el desenvolvimiento de las empresas de capital nacional; propender al autoabastecimiento en aquellos sectores o ramas consideradas fundamentales en pos de acelerar la integración regional, contribuir al desarrollo de una tecnología local capaz de romper los lazos de dependencia con los centros industriales, así como fomentar la obtención de divisas por vía de la exportación de productos manufacturados. Uno de los principales instrumentos consistía en la fijación de los derechos de importación y exportación conducentes a la protección de la producción nacional, así como el establecimiento de restricciones cuantitativas y cualitativas a la importación y exportación.

Otra herramienta fundamental que fijaba dicha ley era el establecimiento de reembolsos y reintegros a las exportaciones, con el objetivo de compensar los desequilibrios de la estructura económica y equiparar los precios de los productos industriales argentinos con los del mercado internacional. La fijación de los mismos, tomaría en consideración el ingreso neto de divisas que dichas exportaciones producirían, buscándose promocionar, especialmente, la exportación de productos fabricados por empresas de capital nacional con tecnología local. Estos elementos, por lo tanto, respondían a pilares fundamentales del programa 
económico (en particular, el estímulo a las empresas de capital nacional y el dinamismo de las exportaciones industriales), considerado este último como uno de los factores que permitiría superar definitivamente el estrangulamiento externo y otorgarle sustentabilidad a la industrialización.

Esta medida de fomento a las exportaciones se complementaba con medidas promocionales que buscaban expandir las mismas y diversificar los mercados a partir de acuerdos bilaterales, especialmente en lo referente a países latinoamericanos y del bloque socialista.

Por otro lado, a partir de las leyes $\mathrm{N}^{\circ} 20.535$ y 20.573 , sancionadas en septiembre de 1973, se establecían nuevas facultades para las Juntas Nacionales de Carnes y de Granos (León y Rossi, 2003), por medio de las cuales el Estado buscaba controlar el comercio externo de dichos productos para asegurar una adecuada colocación de los saldos exportables y garantizar los precios de los productores. De lo que se trataba era del derecho del Estado a comprar y vender la totalidad de las exportaciones agropecuarias, es decir, de una nacionalización parcial del comercio exterior.

Otra cuestión sustancial que el gobierno se proponía tratar era la relativa al uso y tenencia de la tierra. Dos legislaciones merecen especial atención: el impuesto a la renta normal potencial de la tierra, y el anteproyecto de Ley Agraria. La ley $\mathrm{N}^{\circ} 20.538$, sancionada en septiembre de 1973, establecía un impuesto a la renta potencial normal de las explotaciones agropecuarias que debería comenzar a regir a partir de enero de 1975 . En vez de recaer este impuesto sobre la producción (como sucedía hasta el momento), lo cual desalentaba la expansión de la actividad, se establecería en base a la productividad "normal" y "potencial" de la tierra de cada unidad económica de explotación, tomando en consideración para el cálculo del mismo tanto el rubro de producción como las zonas de características ecológico-económicas en que podían agruparse las tierras agrarias del país. ${ }^{6}$ Por su parte, el anteproyecto de Ley Agraria, propuesto pero nunca aprobado por el Congreso, disponía la expropiación de las tierras improductivas, proponiendo su explotación bajo regímenes de propiedad estatal o cooperativa (Rougier y Fiszbein, 2006: 185).

Otro de los puntos centrales del programa consistía en la reforma del sistema financiero, tendiente a reforzar la capacidad regulatoria del Estado. La

6 De esta manera, el establecimiento de este impuesto buscaba premiar a los productores más eficientes, ya que, al tratarse de un impuesto fijo, castigaría en mayor medida a los que menos producían. 
nacionalización de los depósitos, llevada a cabo a partir de la Ley $\mathrm{N}^{\circ} 20.520$, establecía que todas las entidades del sector debían transferir sus depósitos al Banco Central de la República Argentina (BCRA), estando imposibilitadas de girar y utilizar los fondos sin autorización de este último. Asimismo, el BCRA detentaba la capacidad de determinar la cartera máxima de los préstamos de cada banco, pudiendo favorecer a algunos en detrimento de otros, así como de fijar las comisiones por depósitos y la tasa de redescuento de los préstamos.

\section{LAS CONSECUENCIAS DE LA POLÍTICA IMPLEMENTADA. LA EVOLUCIÓN DE ALGUNOS DE LOS PRINCIPALES INDICADORES ECONÓMICOS}

Como se señaló en el primer apartado, el Plan Trienal preveía un considerable crecimiento de la economía entre 1973 y 1977, que debía resultar superior al incremento del consumo. De acuerdo a estas proyecciones, el mismo se encontraría asociado a un incremento sustantivo en el nivel de la formación de capital y, en particular, de la inversión pública. No obstante, la mayoría de los indicadores económicos más relevantes tuvo una evolución que distó considerablemente de las proyecciones delineadas.

Una de las primeras cuestiones que hay que considerar es la evolución del producto bruto interno. En tal sentido, resulta sumamente relevante que, continuando con lo acontecido desde 1964, durante la gestión de Gelbard aquél tuvo un crecimiento ininterrumpido, que en ciertos trimestres llegó a superar el 6\% que no se alejaba considerablemente de las metas establecidas. Tanto el producto industrial como el agropecuario en 1973 y 1974, tuvieron incrementos que se encontraban en consonancia con el comportamiento del producto agregado. No obstante, tanto el consumo como la inversión se desenvolvieron de manera muy diferente a la prevista. El primero evolucionó positiva y prácticamente durante todo este periodo a la par del crecimiento del PIB (incluso en ciertos trimestres por encima de este último), lo que supone el no cumplimiento de la meta de menor crecimiento relativo del mismo establecida en el Plan Trienal.

La inversión, por su parte, tuvo un comportamiento negativo desde el segundo trimestre de 1973 hasta igual periodo de 1974, cuando creció solamente el $0.3 \%$ (Gráfica 1). Resulta significativo que todos los componentes de la misma tuvieron caídas a partir de la asunción del nuevo gobierno, destacándose la retracción, dentro de la inversión en equipo durable, de equipo de transporte, y 
tanto de la construcción pública ${ }^{7}$ como -en menor medida- de la privada. En tal marco, puede considerarse que la contracción de la inversión constituía la respuesta inmediata de una parte significativa de los empresarios a la política de ingresos implementada, en tanto la misma suponía la restricción de trasladar los incrementos de costos (incluidos los salariales) a los precios. Esta retracción en la acumulación de capital afectaba la posibilidad de concretar las metas primordiales del plan económico gubernamental, ya que la misma constituía la base de sustentación de la política redistributiva del ingreso y de la fuerte expansión de la economía propuesta por el gobierno.

Gráfico 1. Evolución interanual del producto bruto interno, del consumo y de la inversión fija 1973-1974 (en porcentajes)

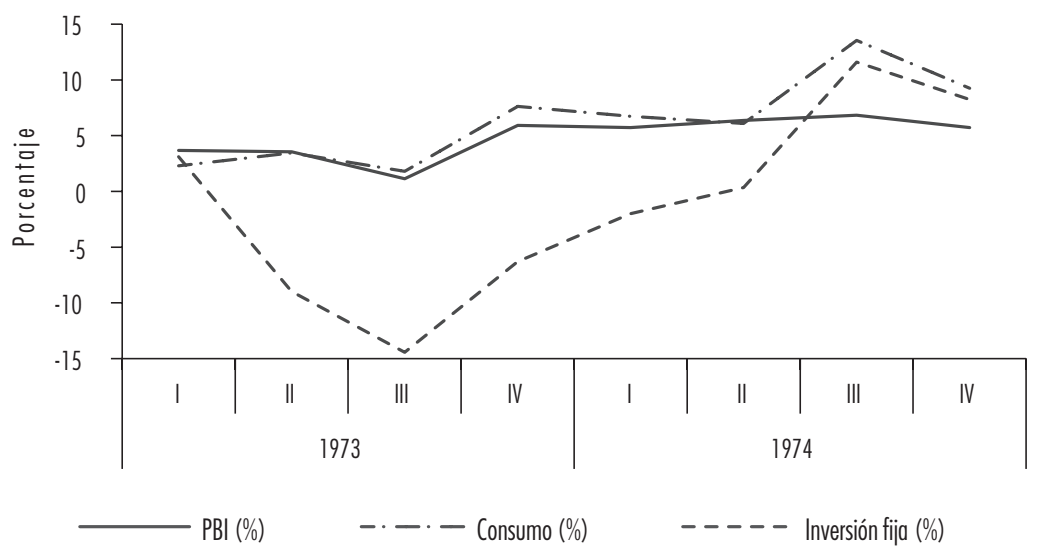

Fuente: elaboración propia con base en datos de FIDE.

Por otro lado, resulta relevante la evolución de varios indicadores en el marco de la política implementada de precios y salarios, que pretendía reducir sustantivamente los niveles inflacionarios y lograr, conjuntamente, un incremento del salario real y de la participación de los asalariados en el ingreso.

Durante los primeros meses de su implementación, el Pacto Social tuvo un resultado positivo en términos de la estabilización del nivel de precios (entre junio y noviembre de 1973, el incremento intermensual del nivel de precios

$7 \quad$ Respecto de la importancia de la inversión pública para la dinámica de acumulación, véase Vitelli (1990: 325). 
minoristas fue en promedio de $0.1 \%$ ), lo cual se encuentra vinculado tanto al poder de arbitraje del nuevo gobierno, como al propicio escenario internacional. Durante ese año los términos del intercambio habían resultado sumamente favorables, encontrando niveles récord en términos históricos y teniendo como correlato un significativo superávit comercial para el país.

En este contexto, la evolución del salario real daba cuenta de una cierta estabilización del mismo en la segunda mitad de 1973, luego de que en el mes de junio, con el incremento inicial en las remuneraciones, se recuperaran los niveles de principios de año. No obstante, a partir de diciembre de dicho año se produjo una reducción del salario real, marco en el cual los sindicatos presionaron y "consiguieron" incrementos, primero a partir de abril de 1974, y luego en noviembre de ese mismo año. Estos últimos lograron mantener el poder adquisitivo del salario solamente, ya que los mismos fueron rápida y crecientemente licuados por el aumento en el nivel de precios (Gráfica 2).

Gráfico 2. Evolución del salario real, enero de 1973-diciembre de 1974*

(base enero 1968=100)

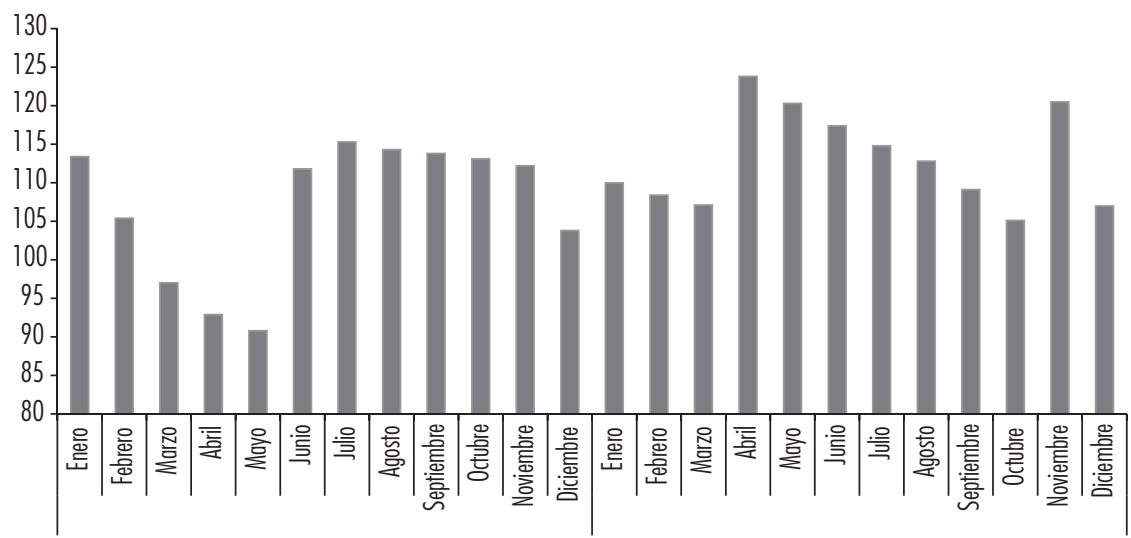

1973

1974

- Salario real* (enero 1968=100)

* Salario básico de convenio de peón industrial.

Fuente: Elaboración propia con base en datos de Jelín (1977).

En tal sentido, si bien durante el primer año de su implementación se logró controlar el incremento del nivel de precios, fue precisamente a partir del segundo trimestre de 1974 cuando la inflación comenzó a resultar un "problema" en términos de la viabilidad del esquema económico. La misma se encontraba asociada, tal como sostiene Canitrot (1978: 34) a la renegociación de los 
Acuerdos de Compromiso de marzo de 1974, situación que -en un contexto de "inflación importada" y de consecuente incremento de costos vinculados a la abrupta modificación del escenario internacional ${ }^{8}$ - reinició en forma exacerbada la disputa por la redistribución del ingreso, dado que los empresarios comenzaron a violar sistemáticamente los precios máximos establecidos y las organizaciones gremiales a luchar por nuevos incrementos salariales que compensaran la creciente inflación.

En otro orden, puede sostenerse que uno de los principales logros del plan económico fue reducir sustancialmente la desocupación. Mientras el Plan Trienal estimaba una desocupación urbana para el año 1974 de 5\%, en octubre de dicho año la misma fue de tan sólo 3.4\%. De esta manera, prácticamente se lograba el cumplimiento de la meta de alcanzar el pleno empleo. Ahora bien, de acuerdo con la evolución del producto y de inversión reseñados anteriormente, puede sostenerse que ésta se logró a partir de la ocupación de capacidad productiva instalada (y no mediante un proceso de acumulación de capital) lo que, una vez empleada plenamente y en un contexto de incremento del consumo, implicaba nuevas presiones sobre los precios (Ferrer, 1977: 40-41).

Por su parte, resulta sumamente relevante evaluar lo acontecido con la distribución funcional del ingreso, ya que uno de los objetivos primordiales del proyecto económico y político gubernamental era incrementar la participación de los asalariados. En tal marco, resulta relevante que en 1973 y 1974 la misma se incrementó, llegando a representar en este último periodo prácticamente el $50 \%$ del ingreso. ${ }^{9}$

En lo que respecta al sector industrial, en el Plan Trienal se establecía que en estos años, tenderían a aumentar en mayor medida relativamente aquellas actividades que tuvieran una mayor productividad del capital (Poder Ejecutivo Nacional, 1973: 40). No obstante, la evolución del producto bruto industrial da cuenta de que entre los sectores industriales que más crecieron en 1973 y 1974, se encontraban aquéllos destinados a la producción de bienes de consumo no durables, de demanda masiva, como es el caso de Textil, vestido y cuero y de Alimentos, bebidas y tabaco, lo que se encuentra vinculado al incremento de

8 Como consecuencia de la irrupción de la denominada crisis del petróleo hacia finales de 1973, se produjo un incremento de los valores de los productos importados en un contexto de congelamiento de precios, lo que supuso un fuerte aumento de los costos empresarios. Esto se sumaba al derrumbe de los acuerdos de Bretton Woods, que condujo a una importante recesión internacional con altas tasas de inflación.

9 Este proceso redundaba, dado el incremento de los costos salariales por encima de la productividad del trabajo, en una disminución de los márgenes de la rentabilidad empresaria. 
la participación de los asalariados en el ingreso y al aumento del consumo. En contraposición, sectores como Industrias Metálicas Básicas o Química y Otras, crecieron muy por debajo del conjunto de la industria.

En este contexto de mayor desarrollo de los sectores menos capitalintensivos, la productividad de la mano de obra en la industria se mantuvo prácticamente constante durante el periodo, dado que tanto el volumen físico de la producción industrial como los obreros ocupados en el sector tuvieron incrementos similares (Cuadro 3).

Cuadro 3. Evolución del volumen físico de la producción, los obreros ocupados, las horas-obrero trabajadas, la productividad del trabajo y la productividad horaria de la mano de obra en la industria manufacturera, 1973-1974

(índice base $1970=100$ y porcentajes)

\begin{tabular}{|c|c|c|c|c|c|}
\hline & $\begin{array}{l}\text { Volumen fisico } \\
\text { de la producción } \\
\text { (1) }\end{array}$ & $\begin{array}{l}\text { Obreros } \\
\text { ocupados } \\
\text { (II) }\end{array}$ & $\begin{array}{l}\text { Horas-obrero } \\
\text { trabajadas } \\
\text { (III) }\end{array}$ & $\begin{array}{l}\text { Productividad del } \\
\text { trabajo } \\
\text { (I/II) }\end{array}$ & $\begin{array}{l}\text { Productividad } \\
\text { horaria de la } \\
\text { mano de obra } \\
\text { (I/III) }\end{array}$ \\
\hline 1973 & 116.80 & 108.60 & 108.90 & 1.08 & 1.07 \\
\hline Tr. I & 105.60 & 110.20 & 100.40 & 0.96 & 1.05 \\
\hline Tr. $\|$ & 117.30 & 108.10 & 111.40 & 1.09 & 1.05 \\
\hline Tr. III & 117.00 & 106.40 & 111.30 & 1.10 & 1.05 \\
\hline Tr. IV & 127.10 & 109.60 & 112.60 & 1.16 & 1.13 \\
\hline 1974 & 122.70 & 114.80 & 114.00 & 1.07 & 1.08 \\
\hline Tr. I & 109.50 & 116.00 & 106.00 & 0.94 & 1.03 \\
\hline Tr. $\|$ & 126.20 & 114.80 & 118.70 & 1.10 & 1.06 \\
\hline Tr. III & 124.60 & 112.30 & 113.80 & 1.11 & 1.09 \\
\hline Tr. IV & 130.50 & 116.00 & 117.60 & 1.13 & 1.11 \\
\hline \multicolumn{6}{|c|}{ Evolución interanual (\%) } \\
\hline 1973 & $3.5 \%$ & $3.2 \%$ & $2.9 \%$ & $0.3 \%$ & $0.6 \%$ \\
\hline Tr. I & $2.0 \%$ & $1.1 \%$ & $0.8 \%$ & $0.9 \%$ & $1.2 \%$ \\
\hline Tr. II & $1.6 \%$ & $2.5 \%$ & $1.9 \%$ & $-0.9 \%$ & $-0,4 \%$ \\
\hline Tr. III & $0.9 \%$ & $3.6 \%$ & $2.9 \%$ & $-2.6 \%$ & $-1,9 \%$ \\
\hline Tr. IV & $9.3 \%$ & $5.6 \%$ & $6.0 \%$ & $3.5 \%$ & $3,1 \%$ \\
\hline 1974 & $5.1 \%$ & $5.7 \%$ & $4.7 \%$ & $-0.6 \%$ & $0.4 \%$ \\
\hline Tr. I & $3.7 \%$ & $5.3 \%$ & $5.6 \%$ & $-1.5 \%$ & $-1.8 \%$ \\
\hline Tr. II & $7.6 \%$ & $6.2 \%$ & $6.6 \%$ & $1.3 \%$ & $1.0 \%$ \\
\hline Tr. III & $6.5 \%$ & $5.5 \%$ & $2.2 \%$ & $0.9 \%$ & $4.2 \%$ \\
\hline Tr. IV & $2.7 \%$ & $5.8 \%$ & $4.4 \%$ & $-3.0 \%$ & $-1.7 \%$ \\
\hline
\end{tabular}

Fuente: elaboración propia en base a datos del CEP. 
Por su parte, del total de proyectos aprobados entre la promulgación de la Ley No 20.560 de Promoción Industrial y 1983, la gran mayoría se presentaron en este periodo: entre 1973 y la instauración de la dictadura militar de 1976 se realizaron 277 presentaciones, la gran mayoría de éstas (prácticamente el 80\%) durante el año 1974, lo que pone en evidencia el "clima" de inversión generado en el marco de dicha ley. En consonancia con el objetivo de otorgar apoyo estatal a aquellas unidades productivas consideradas prioritarias, cabe destacar la gran proporción de proyectos destinados a industrias productoras de bienes intermedios y de capital (Gráfica 3). ${ }^{10}$

Gráfica 3. Proporción de proyectos con promoción presentada entre 1973 y marzo de 1976 en el marco de la Ley 20.560 que fueron aprobados entre 1973 y 1983, según divisiones industriales (en porcentajes)

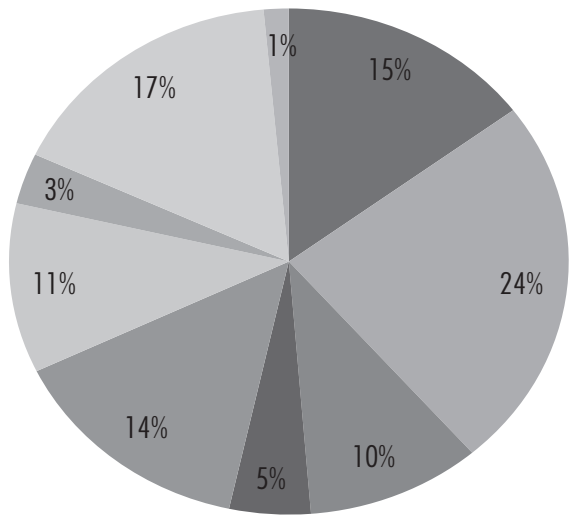

$$
\begin{aligned}
& \text { Alimentos, bebidas y tabaco } \\
& \text { Textiles, confecciones y cuero } \\
& \text { Madera y muebles } \\
& \text { - Papel, imprenta y publicaciones } \\
& \text { Productos químicos } \\
& \text { Minerales no metálicos } \\
& \text { Industrias metálicas básicas } \\
& \text { Productos metálicos, maquinaria y equipos } \\
& \text { Otras manufacturas }
\end{aligned}
$$

Fuente: Elaboración propia con base en Azpiazu (1986).

Respecto al comercio exterior cabe señalar que, si bien el año 1973 había tenido un superávit comercial superior a los 1,000 millones de dólares a partir del tercer trimestre de 1974, vinculado a la modificación abrupta del escenario internacional, la balanza comercial se tornó deficitaria. El significativo incremento de las importaciones durante el periodo se encuentra asociado fundamentalmente al aumento de los precios de las mismas, como consecuencia del

10 No obstante, dada la evolución del producto sectorial anteriormente señalada, y en estrecha asociación con la evolución del consumo y de la distribución del ingreso, puede sostenerse que la producción de bienes de consumo masivo resultó mucho más dinámica que la de los bienes "estratégicos" que buscaba priorizar el gobierno a partir de proyectos promocionados. 
cambio señalado en el contexto económico mundial (en dicho año, las importaciones medidas en cantidades crecieron sólo 7\%), lo cual puso en evidencia cierta dependencia de la importación de insumos producidos en el exterior para el funcionamiento de la actividad industrial del país. No obstante, el año cerró con una balanza comercial positiva, si bien mucho menor que la del año anterior (U\$S $295 \mathrm{M})$.

Asimismo, cabe analizar el comercio exterior en el marco de la propuesta del gobierno, particularmente en lo referente a la búsqueda de incentivar las exportaciones industriales. En el marco de la modificación del "ciclo corto", durante la segunda etapa de la industrialización sustitutiva las exportaciones industriales crecieron a tasas muy superiores con respecto a las ventas externas totales. Entre 1964 y 1975, la participación de las exportaciones de manufacturas de origen industrial (MOI) dentro del total se incrementó más de 12 puntos porcentuales, llegando a representar $20 \%$ del total. Resulta significativo que el mayor dinamismo de las MOI se produjo en el periodo correspondiente al tercer gobierno peronista, por lo que podría sostenerse que -en el marco del incentivo que se les brindó a las mismas durante la segunda etapa de la industrialización sustitutiva- la política de estímulo a las mismas fue relativamente exitosa en términos del significativo dinamismo que obtuvieron. Sobre todo en 1974, año en el que, pese al magro desempeño previamente señalado, las exportaciones industriales crecieron a una tasa que duplicaba la del total de las ventas al exterior (Vitto, 2010: 91).

\section{PRINCIPALES “DEBILIDADES” DEL PROGRAMA ECONÓMICO}

En este marco, puede reflexionarse sobre las principales debilidades de la política económica implementada durante la gestión de Gelbard, asociadas fundamentalmente al lugar estructural de las fracciones sociales y del capital en que dicho plan estaba sustentado. Varias cuestiones pueden sostenerse en este sentido.

En primer lugar, la absorción del aumento salarial que conllevó la implementación del Pacto Social había pesado con mayor fuerza en las industrias que resultaban mano de obra-intensivas, las cuales, como sostiene Di Tella (1983: 197), constituían la base política de la CGE, que a su vez era una de las principales partes "fundantes" de la política en cuestión. Es en tal sentido que puede sostenerse que una de las principales limitaciones de la política económica de corto plazo es que la misma perjudicaba en mayor medida a los sectores "aliados" -la "burguesía nacional”- que además eran estructuralmente más débiles y con menor capacidad de afrontar una disminución en el nivel de beneficios. Este escenario explicaría, pese a su adhesión "ideológica” a la política implementada, 
la "participación" de una parte de estos sectores en el desabastecimiento y en el mercado negro.

En segundo lugar, esta situación se encuentra estrechamente asociada a un aspecto que es mencionado por varios autores que estudian el periodo (Di Tella, 1983: 203; Canitrot, 1975: 335): la política de congelamiento de precios sólo resulta efectiva en un determinado momento para contrarrestar expectativas, aplicada en forma temporaria. En el caso en cuestión, la prolongación de la misma ante un cambio en el escenario internacional que implicaba un fuerte incremento de los insumos importados generaba significativas pérdidas de rentabilidad que tuvieron un rol primordial en la explicación de la situación descrita en el párrafo anterior. En un contexto de cambio en el escenario internacional, el programa terminaba afectando a los principales sectores en que debía sustentarse.

En tal sentido, resulta relevante que la violación a la política de precios máximos no provino solamente de sectores adversarios al gobierno sino también de empresarios que adherían ideológicamente a los lineamientos primordiales de la política implementada. Dado que la CGE acompañó la totalidad de la gestión de Gelbard, no se encontraba en condiciones de articular el descontento de sus miembros, lo cual resultaba significativo ya que, como seńala Torre (2004: 77), habría sido el sector de las medianas y pequeñas empresas, que se encontraban menos sujetas a los controles oficiales (y a la vez, habían sido las más perjudicadas por la política de incrementos salariales), de donde habrían provenido las violaciones más flagrantes de la política de precios.

Esto se sumaba a un rol subordinado de la CGT en el Pacto Social, ya que los dirigentes sindicales se veían compelidos a aceptar su participación, relegando una de las cuestiones más sustantivas de su plataforma: la lucha por el nivel de ingresos. En contraposición, los empresarios conservaban en su poder la decisión de inversión, lo que supone un cierto control sobre variables cruciales de la economía. A esta participación "poco voluntaria" se sumaba que la central obrera era cuestionada y "puesta en jaque" por las bases obreras, que consideraban al Pacto Social como traición, y que se encontraban sumamente movilizadas durante todo este periodo. Si bien los salarios se encontraban congelados, durante el mismo se produjo una proliferación de los conflictos laborales que bregaban tanto por mejoras en las condiciones laborales como por incrementos salariales, que fueron "arrancados" a los empresarios en las luchas en el interior de las fábricas, más allá del congelamiento oficial. Este contexto de movilización presionaba "desde abajo" y condicionaba (desde las bases) el accionar de la CGT.

De lo anterior se desprende que el Pacto Social resultaba cuestionado, en cierta medida, por dos integrantes centrales de la alianza gobernante. A esto 
debe agregarse que, prácticamente desde los inicios del gobierno (pero con mayor intensidad desde la "caída" de Cámpora), los sectores "izquierdistas" (que tuvieron un papel protagónico en la vuelta del peronismo al gobierno) no sólo fueron relegados (y de manera cada vez más acentuada) del proyecto gubernamental, sino que al mismo tiempo se opusieron progresivamente a la política económica implementada. Las organizaciones asociadas a la "juventud" consideraban al Pacto Social como un "proyecto burgués" de patrones y empresarios, que suponía la explotación del pueblo (Baschetti, 1996).

Si estos elementos condicionaban la capacidad de articulación efectiva del proyecto económico propuesto, puede sostenerse asimismo una serie de limitaciones por el lado de las fracciones que se pretendía reestructurar. En tal sentido, se trabajará con dos ejemplos: la política de fomento de la industria de sectores considerados "estratégicos", y la de aliento a las exportaciones industriales.

En cuanto a la promoción de sectores industriales considerados "prioritarios" resulta relevante que, de acuerdo con los datos provistos por Castellani (2009), buena parte de la promoción industrial en proyectos de gran envergadura en ramas estratégicas tenía como beneficiarias a empresas reunidas en grupos económicos (pertenecientes a la denominada "oligarquía diversificada" ${ }^{11}$ ), que tenían un peso significativo en la producción de bienes intermedios. ${ }^{12} \mathrm{Si}$ bien las propuestas provenientes de las pequeñas y medianas empresas concentraron gran parte de la atención en lo referente a la promoción industrial, éstas tuvieron mucha dificultad para concretarse, como resultado de lo cual una gran proporción de los montos de inversión que resultaron aprobados fue absorbida por pocas empresas, especializadas en este tipo de bienes (Rougier y Fiszbein, 2006: 196). De esta manera, pese a que el gobierno pretendía implementar, en lo relativo al sector industrial, una política tendiente a fortalecer a la "burguesía nacional", era la "oligarquía diversificada" la beneficiada en mayor medida por la política de promoción.

11 Esta última engloba a la fracción de la oligarquía que paulatinamente fue diversificando su cartera de inversiones hacia otros rubros económicos, desarrollando una inserción multisectorial en la economía local con intereses en la industria, el agro y otras actividades económicas. En tanto, se consideran integrantes de la burguesía nacional a aquellos capitales locales no integrados en conglomerados empresarios. Una acabada conceptualización de estas fracciones del capital puede encontrarse en Basualdo (2006, 2007).

12 Para un análisis de la composición del valor de producción de los establecimientos industriales con 100 o más ocupados según tipo de empresa y bien elaborado en 1973, véase Basualdo (2006: 89). En tal sentido, este autor destaca que, en dicho año, la "oligarquía diversificada" tenía como principales actividades la producción de bienes intermedios (siderurgia, papel y cartón, acabado textil y cemento). 
A esto debe sumarse que era el capital extranjero el que tenía preponderancia en los núcleos "dinámicos" de la industrialización sustitutiva. Si bien durante el periodo de Gelbard tuvo un mayor dinamismo la producción de bienes de consumo no durables ligados a la "burguesía nacional", esto no invalidaba, por un lado, la situación estructural descrita, y por otro, contradecía algunos de los lineamientos básicos del Plan Trienal (en particular en lo referente a fomentar el desarrollo de actividades capital-intensivas y la producción de ciertos bienes intermedios, rubros en los que el capital extranjero y la "oligarquía diversificada" tenían un predominio indiscutido). Siguiendo lo señalado por De Riz (1987: 140), el dinamismo de estas ramas habría sido en mayor medida resultado de la demanda de los asalariados, efecto de nuevas inversiones, lo que se tradujo en el uso de capacidad instalada ociosa.

Una breve evaluación de los lineamientos del Plan Trienal en referencia a la industria manufacturera pone de relieve algunas de las limitaciones estructurales del proyecto económico. Las líneas básicas de acción al respecto eran:

- Realización acelerada de grandes proyectos, ya formulados, en su mayoría, e iniciación de nuevos proyectos en las industrias productoras de insumos intermedios, referidos básicamente a la siderurgia, aluminio, papel prensa, celulosa, química pesada y petroquímica. En la mayoría de estos sectores había un "predominio estructural" de la "oligarquía diversificada", que era la que resultaba beneficiada en mayor medida por los mecanismos de promoción.

- Promoción de ciertas industrias de bienes de consumo no durable y durable, altamente captadoras de mano de obra, como el caso de la industria textil, diversas ramas del sector "Alimentos y bebidas", etcétera. No obstante, para la mayoría de estas ramas, en las que la "burguesía nacional" tenía predominio, se estimaba un crecimiento inferior al del promedio de la industria.

- Control del crecimiento "exagerado" de ciertas ramas, de modo de adecuar la composición de la producción industrial a la nueva composición de la demanda total de productos industriales, que debía resultar de los objetivos del Plan. No obstante, en referencia a la producción automotriz, se señalaba explícitamente que se justificaría su crecimiento superior al del promedio de la industria en función del abastecimiento del mercado de exportación. Esta política de fomento a las ventas externas industriales, como se verá, tendía a favorecer al capital extranjero.

- Desarrollo prioritario de la industria de bienes de capital en sus diversos aspectos, aumentando sustancialmente la contribución del Estado en este campo. Cabe señalar, en este punto, que de acuerdo con los datos provistos por 
Basualdo (2006: 89), en 1973 el capital extranjero tenía amplia preeminencia en la producción de este tipo de bienes. En este marco resultaba imprescindible un Estado fuerte, con capacidad para incrementar su participación en este rubro para controlar la influencia del capital extranjero, y aumentar y ordenar su participación en la actividad industrial, lo cual constituía una de las falencias intrínsecas del Plan Trienal, como se analizará.

En lo referente al comercio exterior, pese al dinamismo de las exportaciones industriales, que no resultaba menor y daba cuenta de un salto cualitativo en la estrategia de desarrollo implementada, el proyecto económico tenía limitaciones de distinta índole que vale la pena señalar. En primer lugar puede sostenerse que a pesar de su dinamismo, la participación de las manufacturas de origen industrial dentro del total de exportaciones ponía en evidencia la todavía importante gravitación de las colocaciones externas de productos primarios sumadas a las manufacturas de origen agropecuario, lo cual implicaba una dependencia significativa de las exportaciones de este tipo de bienes y, por tanto, del "apoyo" del sector agropecuario en la viabilidad del proyecto económico.

Dentro de las exportaciones industriales, las más significativas en términos tanto de importancia como de dinamismo fueron Maquinaria y aparatos eléctricos y no eléctricos, y Productos Químicos y Hierro y Acero, concentrando alrededor del 90\% de este tipo de exportaciones en 1973 y 1974 (Vitto, 2010: 92). Esta participación se encuentra en consonancia con los rubros más dinámicos de la segunda sustitución de importaciones, en los cuales las actividades metalmecánicas y químicas tenían un indiscutido liderazgo.

En este marco caben varias reflexiones. En primer lugar, el proyecto de promoción de las exportaciones de productos fabricados por empresas de capital nacional y con tecnología local establecido en la Ley $\mathrm{N}^{\circ} 20.545$ chocaba con serias limitaciones, asociadas a la posición estructural que ocupaban las diferentes fracciones del capital durante el periodo. En tal sentido, si el proyecto económico del gobierno buscaba representar, en lo referente al comercio exterior, a los intereses de la burguesía nacional, era el capital extranjero el que resultaba mayormente beneficiado por dicho programa. Como consecuencia de las políticas implementadas en 1973 la burguesía nacional se encontraba debilitada en términos de su posición en la estructura productiva, teniendo peso en las ramas mediana y escasamente concentradas, con una productividad por lo general menor que la de las empresas extranjeras, y un uso más intensivo de mano de obra.

Sin embargo, debe decirse que había un sector relativamente minoritario de la burguesía nacional que sí estaba ligado al núcleo más dinámico de la acumulación de capital orientado a la exportación de bienes. Estas empresas, dedicadas a 
la producción de bienes intermedios, se encontraban vinculadas a las compañías trasnacionales como clientes o proveedoras de las mismas (Canitrot, 1978). Uno de los ejemplos paradigmáticos de este tipo de firmas eran las empresas fabricantes de autopartes, las que resultaban altamente dependientes, en tanto eran las que aprovisionaban a las terminales automotrices, controladas por empresas extranjeras (Arceo, Azpiazu, Basualdo y Wainer, 2009). En tal sentido, si bien este sector de la burguesía nacional se encontraba vinculado a los núcleos dinámicos de esta etapa de la industrialización sustitutiva, su dependencia respecto al capital extranjero no resultaba menor, teniendo por ende serias limitaciones en su capacidad de liderar un proceso de desarrollo. Asimismo, puede considerarse que la estrategia de incentivos a las MOI tenía severos inconvenientes en lo referente a su capacidad de sustentabilidad a mediano/largo plazos, ya que las exportaciones industriales más importantes, controladas en buena medida por empresas trasnacionales, tenían subsidios significativos, con lo cual el costo del desarrollo de dicha política resultaba sumamente elevado para el Estado (Testa, 1975).

En rigor, esto no implicaba problemáticas de corto plazo en cuanto a su impacto en el dinamismo de ambos sectores, sino que operarían sólo a mediano/ largo plazos, es decir, en términos de la consolidación de un sujeto social capaz de llevar adelante un modelo sustentable de desarrollo, y del lugar del Estado en el fomento del mismo. La promoción de la producción y la exportación de bienes industriales favorecían - por el lugar estructural que ocupaban en la economía argentina- a las fracciones económicamente predominantes, lo que quitaba espacio y fuerza para la promoción de la burguesía nacional.

Asimismo, no resulta un dato menor que en un sistema capitalista la respuesta inmediata frente a una caída en la rentabilidad o a un gobierno considerado "opositor", en términos de sus propios intereses, sea la disminución de la inversión. En tal sentido, la baja de la misma durante el periodo da cuenta tanto de la desconfianza de una parte del empresariado hacia el gobierno, como de una réplica frente a la disminución de la rentabilidad en un escenario de incremento de costos y de congelamiento de precios. Esta respuesta empresaria se sumaba así a las estrategias tendientes a eludir el control de precios (mercado negro-desabastecimiento).

Por último, a este contexto de caída de la inversión privada se sumaba la debilidad del Estado de compensarla. En este punto, si bien el Plan Trienal sostenía que la inversión pública tendría un lugar central en la promoción del desarrollo, aquélla se vio limitada, como señala Testa (1975: 46), por el déficit presupuestario que en 1973 cuadriplicó al del año anterior y que fue financiado, fundamentalmente, con reservas del BCRA. 
De esta manera, la inviabilidad del proyecto no se encontraba ligada solamente a la debilidad de la burguesía nacional sino también del propio Estado, incapaz de redireccionar el proceso de desarrollo y de implementar y posibilitar un esquema sustentable a mediano plazo. La misma se encontraba enmarcada dentro de las contradicciones del peronismo, en el cual las disputas en el interior del propio grupo gobernante tenían un lugar central, sobre todo con posterioridad al fallecimiento del líder.

Es en el contexto señalado que, cuando intentaron comenzar a implementarse las medidas que buscaban reestructurar las relaciones dentro del sector agropecuario, y en particular aquéllas asociadas a la estructura de tenencia de la tierra, no tardó en emerger el conflicto con los sectores sociales implicados. De acuerdo a lo señalado por Testa (1975: 56), puede considerarse al anteproyecto de Ley Agraria como el elemento decisivo que rompió las relaciones entre el sector terrateniente y el equipo de Gelbard. A partir del conflicto suscitado en torno a este anteproyecto, en el marco de la muerte de Perón y el cambio del equipo económico, los sectores agrarios pasarían definitivamente a la ofensiva. En este contexto, en el mes de agosto de 1975 se creó la Asamblea Permanente de Entidades Empresarias (APEGE), que reunía al sector empresario industrial, comercial y agrario más poderoso (incluyendo a la oligarquía tanto agropecuaria como "diversificada"), y que sería la encargada de llevar a cabo la ofensiva final contra el tercer gobierno peronista.

\section{BREVES REFLEXIONES FINALES}

La política económica inicial implementada por José Ber Gelbard pretendía, fundamentalmente, una profunda reestructuración del capitalismo argentino a partir del aliento a la denominada "burguesía nacional", en detrimento de los sectores que resultaban económicamente predominantes: el capital extranjero y la "oligarquía diversificada".

En los momentos iniciales, el mayor control estatal sobre el proceso económico -a partir de, por ejemplo, el manejo del crédito y la tasa de interés- permitió amortiguar el impacto de los aumentos salariales sobre la tasa de ganancia, "aceitando" las condiciones para el Pacto Social. No obstante esta situación se resintió cuando cambiaron los términos del intercambio en 1974, poniendo de relieve las deficiencias estructurales de la economía argentina y sus dificultades para hacer frente a las consecuencias del cambio en el contexto internacional. A esto se sumaba, como un detalle no menor, la muerte de Perón y la consiguiente debilidad política del gobierno, así como las disputas en el interior del peronismo. 
Por su parte, la revisión de la política económica llevada a cabo pone de relieve la debilidad del sector del capital que se buscaba beneficiar, y la "fortaleza" estructural de los que se intentaba controlar. De esta manera, puede considerarse que parte de la debilidad de esta política se encuentra asociada a la situación estructural de la economía argentina, y en particular a las características y limitaciones de la burguesía nacional durante el periodo. Sin embargo, este diagnóstico no supone sostener que el giro abrupto que se verificó en la política económica argentina a mediados de 1975 -con el denominado "Rodrigazo"se debió a un agotamiento de la política implementada anteriormente, sino que sobre esta situación de debilidad (tanto de la capacidad interventora del Estado como de las fracciones del capital en que éste se "apoyaba") se montó un proyecto con intereses y objetivos contrapuestos.

\section{BIBLIOGRAFÍA}

Arceo, Nicolás, Daniel Azpiazu, Eduardo Basualdo y Andrés Wainer, "Transformaciones estructurales de la economía argentina. Una aproximación a partir del panel de grandes empresas, 1991-2005", Buenos Aires, Programa Naciones Unidas para el Desarrollo (PNUD), 2009.

Azpiazu, Daniel, Eduardo Basualdo y Miguel Khavisse, El nuevo poder económico en la Argentina de los años ochenta, Edición definitiva, Buenos Aires, Siglo xxi Editores, 2004.

Azpiazu, Daniel y Miguel Khavisse, "La concentración en la industria argentina en 1974", Buenos Aires, Centro de Economía Transnacional, 1983.

Baschetti, Roberto, comp., Documentos 1973-1976. Vol. I. De Cámpora a la ruptura, La Plata, De la Campana, 1996.

Basualdo, Eduardo, Estudios de Historia Económica Argentina desde mediados del siglo XX a la actualidad, Buenos Aires, Siglo XXI Editores, 2006.

Basualdo, Eduardo, "Concepto de patrón o régimen de acumulación y conformación estructural de la economía”, Documento núm. 1, Maestría en Economía Política Argentina, Área de Economía y Tecnología FlACsoArgentina, 2007.

Basualdo, Eduardo, "La distribución del ingreso en Argentina y sus condicionantes estructurales", en Memoria Anual, Centro de Estudios Legales y Sociales (CELS), Buenos Aires, 2008, pp. 307-326.

Braun, Oscar y Leonard Joy, "Un modelo de estancamiento económico. Estudio de caso sobre la economía argentina”, en Desarrollo Económico, núm. 80, Vol. 20, Buenos Aires, IDES, enero-marzo 1981, pp. 585-604. 
Brodersohn, Mario, "Política económica de corto plazo, crecimiento e inflación en la Argentina, 1950-1972", en Problemas económicos argentinos, Buenos Aires, Ediciones Macchi, 1973, pp. 3-64.

Canitrot, Adolfo, "La experiencia populista de redistribución de ingresos", en Desarrollo Económico, núm. 59, Vol. 15, Buenos Aires, IDES, octubrediciembre 1975, pp. 331-351.

Canitrot, Adolfo, "La viabilidad económica de la democracia: un análisis de la experiencia peronista 1973-1976”, Serie Estudios Sociales, núm. 11, Buenos Aires, CEDEs, 1978.

Castellani, Ana, Estado, empresas y empresarios. La construcción de ámbitos privilegiados de acumulación entre 1966 y 1989, Buenos Aires, Prometeo Libros, 2009.

De Riz, Liliana, Retorno y derrumbe. El último gobierno peronista, Buenos Aires, Hyspamérica, 1987.

Diamand, Marcelo, "El péndulo argentino: ¿empate político o fracasos económicos?”, en Pensar la República, Fundación Piñero Pacheco, Buenos Aires, Editorial Persona a Persona, 1977.

Di Tella, Guido, Perón-Perón, 1973-1976, Buenos Aires, Hyspamérica, 1983.

Ferrer, Aldo, Crisis y alternativas de la politica económica argentina, Buenos Aires, Fondo de Cultura Económica, 1977.

León, Carlos Alberto y Carlos Alberto Rossi, "Aportes para la historia de las instituciones agrarias de la Argentina (I): la Junta Nacional de Granos", en Realidad Económica, núm. 196, Buenos Aires, IADE, mayo-junio de 2003, pp. 84-101.

Poder Ejecutivo Nacional, Plan Trienal para la Reconstrucción y la Liberación Nacional, Buenos Aires, Editorial Codex, s.A., 1973.

Rougier, Marcelo y Martín Fiszbein, La frustración de un proyecto económico. El gobierno peronista de 1973-1976, Buenos Aires, Manantial, 2006.

Testa, Víctor, "Aspectos económicos de la coyuntura actual (1973-1975)", Serie Polémica, núm. 5, Buenos Aires, cicso, 1975.

Torre, Juan Carlos, El gigante invertebrado. Los sindicatos en el gobierno, Argentina 1973-1976, Buenos Aires, Siglo Veintiuno Editores, 2004.

Vitelli, Guillermo, Las lógicas de la economía argentina, Buenos Aires, Prendergast, 1990.

Vitto, Cecilia, "El comercio internacional en el tercer gobierno peronista y en la posconvertibilidad", en Realidad Económica, núm. 254, Buenos Aires, IADE, agosto-septiembre de 2010, pp. 82-109. 